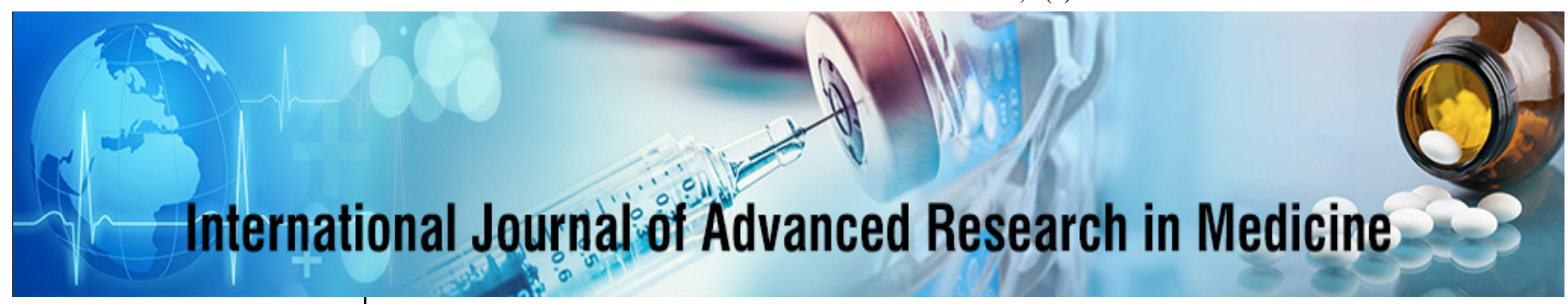

E-ISSN: 2706-9575

P-ISSN: 2706-9567

IJARM 2021; 3(2): 483-485

Received: 05-05-2021

Accepted: 28-05-2021

Dr. Guruprasad KG

Associate Professor, Department of Psychiatry, Index Medical College, Hospital and Research Centre, Index City, Indore, Madhya Pradesh, India
Corresponding Author: Dr. Guruprasad KG Associate Professor, Department of Psychiatry, Index Medical College, Hospital and Research Centre, Index City, Indore, Madhya Pradesh, India

\section{A study of psychological effect of COVID 19 during the pandemic}

\section{Dr. Guruprasad KG}

DOI: https://doi.org/10.22271/27069567.2021.v3.i1h.272

\begin{abstract}
Background: The Covid 19 outbreak was associated with tremendous public anxiety in the affected countries, and it resulted in thousands of mortality cases, fear, anxiety, and psychosocial stress among the population, in addition to economic losses. Consequently, it is crucial to understand the extent of impact for such pandemics on mental health and other aspects of life.

Aims and Objectives: To study the psychological effect of covid 19 during the pandemic.

Materials and Methods: This study was done in Index Medical College, hospital and Research Centre, Index City, Indore, Madhya Pradesh. The study was done in two phases. The study was done from Feb 2021 to April 2021. A set of validated questionnaire was given to the students, teachers and patients. Local population was also involved and the questionnaire was circulated online.

Results: Majority of them had increased work pressure. And their IES-R scores related to it.

Conclusion: This study was successful to find the psychological effect of covid 19 in our population during the pandemic.
\end{abstract}

Keywords: Psychology, mental health, covid-19

\section{Introduction}

In the oct. of 2010 a disease cluster which presented with atypical pneumonia was reported in China ${ }^{[1]}$. The disease was found to be primarily contagious and was transmitted through droplet infection ${ }^{[2]}$. The patients presented with a plethora of signs and symptoms including raised body temperature, cough, headache, nausea, vomiting, anorexia, diarrhea, dyspnea, multiple organ dysfunctions ${ }^{[3]}$. Majority of the patients reported only mild infections and were all right after a week or two ${ }^{[4]}$. But in a minor number of cases patients progressively develop serious complications, including sepsis, acute respiratory failure, metabolic acidosis, heart failure, kidney injury, hypoxic encephalopathy, and eventually die of the illness ${ }^{[5]}$. The study retrospectively reviewed the Case files of patients with COVID-19 and compared the hematological and biochemical characteristics between survivors and non-survivors. Considering high transmission and infectivity patterns, World Health Organisation announces it as an emergency of public health concern on March 31, $2020^{[6]}$. In the initial phase of the disease outbreak, the mortality ranges from 2 to 5\%, much higher in the elderly ${ }^{[3]}$. The mortality in coronavirus cases admitted in Wuhan city reached $7 \%$ in the outbreak's initial days ${ }^{[7]}$. This study puts in an effort to find the psychological effect of covid 19 during the pandemic.

\section{Aims and Objectives}

To study the psychological effect of covid 19 during the pandemic

\section{Materials and Methods}

This study was done in Index Medical College, hospital and Research Centre, Index City, Indore, Madhya Pradesh. The study was done in two phases. The study was done from Feb 2021 to April 2021.

A set of validated questionnaire was given to the students, teachers and patients. Local population was also involved and the questionnaire was circulated online.

\section{Exclusion criteria}

Patients who did not consent. 


\section{Methodology}

The Impact of Event Scale-Revised (IES-R) was used to assess the psychological impact of COVID-19 among adults residing in this region. The IES- $\mathrm{R}$ is a self-administered questionnaire containing 22 items and it has been previously translated and validated in the English. The IES-R has also been used to measure symptomatology experienced during the COVID-19 pandemic in Saudi Arabia, Egypt, Italy, and China ${ }^{[15]}$. The response for each question was scored based on a five-point Likert scale ranging from 0 (not at all) to 4 (extremely) and generated a total score (ranging from 0 to 88). The total IES-R score was considered normal (from 0 to 23); indicative of mild (from 24 to 32); moderate (from 33 to 36$)$; or severe ( $\geq 37$ ) psychological impact.
Statistical Analysis: Chi square test.

\section{Results}

Table 1: Age

\begin{tabular}{|c|c|c|}
\hline Total & Mean Age & SD \\
\hline 392 & 41.83 years & \pm 9.28 years \\
\hline
\end{tabular}

Table 2: Sex Distribution

\begin{tabular}{|c|c|c|}
\hline Total & Male & Female \\
\hline 392 & 207 & 185 \\
\hline
\end{tabular}

Table 3: Association of IES-R scores with negative mental health

\begin{tabular}{|c|c|c|c|c|c|c|}
\hline \multirow{2}{*}{ Variables: } & \multicolumn{5}{|c|}{ IES-R Categories } & \multirow{2}{*}{$P$ value } \\
\hline & Total & Normal & Mild & Moderate & Severe & \\
\hline Increased stress & & \multirow{3}{*}{2} & \multirow{3}{*}{187} & \multirow{3}{*}{142} & \multirow{3}{*}{61} & \multirow{3}{*}{$<0.001$} \\
\hline Yes & 390 & & & & & \\
\hline No & 2 & & & & & \\
\hline Increased Finan & & \multirow{3}{*}{94} & \multirow{3}{*}{67} & \multirow{3}{*}{143} & \multirow{3}{*}{88} & \multirow{3}{*}{$<0.001$} \\
\hline Yes & 298 & & & & & \\
\hline No & 94 & & & & & \\
\hline Increased stress & & \multirow{3}{*}{162} & \multirow{3}{*}{79} & \multirow{3}{*}{48} & \multirow{3}{*}{103} & \multirow{3}{*}{$<0.001$} \\
\hline Yes & 230 & & & & & \\
\hline No & 162 & & & & & \\
\hline Felt afraid duri & & \multirow{3}{*}{135} & \multirow{3}{*}{57} & \multirow{3}{*}{86} & \multirow{3}{*}{114} & \multirow{3}{*}{$<0.001$} \\
\hline Yes & 257 & & & & & \\
\hline No & 135 & & & & & \\
\hline Felt apprehe & & \multirow{3}{*}{110} & \multirow{3}{*}{70} & \multirow{3}{*}{75} & \multirow{3}{*}{137} & \multirow{3}{*}{$<0.001$} \\
\hline Yes & 283 & & & & & \\
\hline No & 110 & & & & & \\
\hline Felt helpl & & \multirow{3}{*}{90} & \multirow{3}{*}{85} & \multirow{3}{*}{154} & \multirow{3}{*}{63} & \multirow{3}{*}{$<0.001$} \\
\hline Yes & 302 & & & & & \\
\hline No & 90 & & & & & \\
\hline
\end{tabular}

\section{Discussion}

The novel coronavirus, later designated as COVID-19, is an infectious disease that can spread among humans. In response to this global health crisis, quarantine and lock down measures were implemented by international and government health organizations to contain the rapid spread of the virus. Further measures included suspension of flights, avoidance of large gatherings, mandatory use of face mask in many countries, social distancing, teleworking, home-schooling of children and health orders to stay at home ${ }^{4}$. While the WHO and worldwide health authorities are actively working on containing the outbreak, such a period of health crisis has significant repercussions on human health and welling, accompanied by psychological distress and related symptoms such as stress, panic and anxiety in the general population [5]. Moreover, psychological impact is considered to be more profound in comparison to the Severe Acute Respiratory Syndrome (SARS) epidemic in 2003, due to the extensive social media exposure and increased global connectivity [6, 7]. SARSrelated psychological problems have been reported to be prevalent mainly among healthcare workers and SARS survivors [8, 9]. In 2012, the Middle East respiratory syndrome coronavirus (MERS-CoV) was first identified in Saudi Arabia ${ }^{[10]}$. The spread of MERS-CoV across the Middle East was linked to the transmission of the pathogen from Dromedary camels to humans ${ }^{[11]}$. The MERS-CoV outbreak was associated with tremendous public anxiety in the affected countries, and it resulted in thousands of mortality cases, fear, anxiety, and psychosocial stress among the population, in addition to economic losses ${ }^{[12,13]}$. Consequently, it is crucial to understand the extent of impact for such pandemics on mental health and other aspects of life ${ }^{[14,15]}$. This study puts in an effort to find the same to what has happened in our population and has succeeded in doing the same.

\section{Conclusion}

This study was successful to find the psychological effect of covid 19 during the pandemic. The mental health has been affected and it is very important to understand the role of Psychiatrists during the pandemic.

\section{References}

1. WHO. Pneumonia of unknown cause-China: World Health Organization; 2020 [19 February 2021].

2. Cucinotta D, Vanelli M. WHO declares COVID-19 a pandemic. Acta bio-medica: Atenei Parmensis 2020;91(1):157-60. pmid:32191675.

3. WHO. COVID-19 Weekly epidemiological update-16 February 2021: World Health Organization 2020 [19 February 2021].

4. Bedford J, Enria D, Giesecke J, Heymann DL, Ihekweazu C, Kobinger G et al. COVID-19: towards controlling of a pandemic. The Lancet 2020;395(10229):1015-8. pmid:32197103. 
5. Wang C, Pan R, Wan X, Tan Y, Xu L, Ho CS et al. Immediate psychological responses and associated factors during the initial stage of the 2019 coronavirus disease (COVID-19) epidemic among the general population in China. International journal of environmental research and public health 2020;17(5):1729. pmid:32155789.

6. Gao J, Zheng P, Jia Y, Chen H, Mao Y, Chen S et al. Mental health problems and social media exposure during COVID-19 outbreak. PloS one 2020;15(4):e0231924. pmid:32298385.

7. Depoux A, Martin S, Karafillakis E, Preet R, WilderSmith A, Larson H. The pandemic of social media panic travels faster than the COVID-19 outbreak. Oxford University Press 2020.

https://doi.org/10.1093/jtm/taaa031 pmid:32125413.

8. Lee AM, Wong JG, McAlonan GM, Cheung V, Cheung C, Sham PC et al. Stress and psychological distress among SARS survivors 1 year after the outbreak. The Canadian Journal of Psychiatry 2007;52(4):233-40. pmid:17500304.

9. Chua SE, Cheung V, Cheung C, McAlonan GM, Wong JW, Cheung EP et al. Psychological effects of the SARS outbreak in Hong Kong on high-risk health care workers. The Canadian Journal of Psychiatry 2004;49(6):391-3. pmid:15283534

10. Zaki AM, Van Boheemen S, Bestebroer TM, Osterhaus $\mathrm{AD}$, Fouchier RA. Isolation of a novel coronavirus from a man with pneumonia in Saudi Arabia. N Engl J Med 2012;367(19):1814-20. Epub 2012/10/19. pmid:23075143.

11. Alagaili AN, Briese T, Mishra N, Kapoor V, Sameroff SC, Burbelo PD et al. Middle East respiratory syndrome coronavirus infection in dromedary camels in Saudi Arabia. mBio 2014;5(2):e00884-14. Epub 2014/02/27. pmid:24570370

12. Al Shehri AM. A lesson learned from Middle East respiratory syndrome (MERS) in Saudi Arabia. Med Teach 2015;37(1):S88-93. Epub 2015/03/25. pmid:25803593.

13. Al-Rabiaah A, Temsah M-H, Al-Eyadhy AA, Hasan GM, Al-Zamil F, Al-Subaie S et al. Middle East Respiratory Syndrome-Corona Virus (MERS-CoV) associated stress among medical students at a university teaching hospital in Saudi Arabia. Journal of Infection and Public Health 2020;13(5):687-91. pmid:32001194

14. Torales J, O’Higgins M, Castaldelli-Maia JM, Ventriglio A. The outbreak of COVID-19 coronavirus and its impact on global mental health. International Journal of Social Psychiatry 2020:0020764020915212. pmid:32233719

15. Davico C, Ghiggia A, Marcotulli D, Ricci F, Amianto F, Vitiello B. Psychological Impact of the COVID-19 Pandemic on Adults and Their Children in Italy. SSRN 3576933. 2020. 